\title{
An asymptomatic young woman with abnormal manubrium sterni: diagnosis and discussion
}

\author{
Dae Hee Han • Myeong Im Ahn • Jung Im Jung • \\ Seog Hee Park
}

Published online: 7 August 2009

(C) ISS 2009

\section{Diagnosis \\ Complete fissure of the manubrium sterni.}

\section{Discussion}

First developing from a pair of longitudinal mesenchymal condensations in utero, the right and left sternal bars meet along the midline and fuse to form a single cartilaginous rod. Fusion commences at the manubrium and proceeds caudad [1]. Incomplete fusion of lower sternebrae results in well-known bony defects variously named sternal foramen, cleft or fissure [2].

Although clefts and foramina are commonly found in the corpus sterni, description of manubrial fissure or foramen had been sparse [3-5] before the study by Yekeler et al., who reported a manubrial cleft in the sterna of six of 1,000 adults [2]. In all of the six patients the cleft was confined to the superior portion of the bone, associated with a sclerotic band just inferior to it in five of them. To our knowledge, a complete manubrial cleft is extremely rare, with only two

The case presentation can be found at doi: 10.1007/s00256-009-0755-1.

D. H. Han • M. I. Ahn $(\bowtie) \cdot$ J. I. Jung $\cdot$ S. H. Park

Department of Radiology, Seoul St. Mary's Hospital,

College of Medicine, The Catholic University of Korea,

505 Banpo-dong, Seocho-gu,

Seoul 137-701, Korea

e-mail: ami@catholic.ac.kr

D. H. Han

e-mail: lepolder@gmail.com

J. I. Jung

e-mail: jijung@catholic.ac.kr

S. H. Park

e-mail: parksh@catholic.ac.kr cases having been reported in the non-English literature [3, 4]. In one of the two cases, reported in 1979, Botsch et al. used conventional tomography to diagnose complete fissure of the manubrium [4], which showed slightly jagged and sclerotic medial margins of the right and left hemimanubria and an inverted-Y shape, almost identical to that in our patient, formed by the interhemimanubrial and hemimanubriosternal joints (Fig. $1 \mathrm{~b}$ and $\mathrm{c}$ in the case presentation).

It is difficult to postulate the developmental origin of a manubrial fissure. However, we suppose that there might be two possible mechanisms: first, on rare occasions, the cephalo-most part of the sternal bar might have been left unfused in utero. Second, there might have been some muscular dynamics facilitating horizontal segmentation of the manubrium at a later stage, similar to diversified movements of the forelimbs facilitating longitudinal segmentation of the sternum [6].

Now that thin-section CT scanning of the bony thorax is becoming routine in clinical practice, we believe that more cases of this condition will be found in the future.

\section{References}

1. Stark P. Midline sternal foramen: CT demonstration. J Comput Assist Tomogr. 1985;9:489-90.

2. Yekeler E, Tunaci M, Tunaci A, Dursun M, Acunas G. Frequency of sternal variations and anomalies evaluated by MDCT. AJR Am J Roentgenol. 2006;186:956-60.

3. Saris A, Quinard J, Mauduit A, Zumbiehl J. Congenital fissure of the manubrium sterni. J Radiol Electrol Med Nucl. 1964;45:276-7.

4. Botsch H, Schmidt L. Unusual shape of a fissure of the sternal manubrium. Rofo Fortschr Geb Rontgenstr Neuen BildgebVerfahr. 1979;131:563-4.

5. Moore MK, Stewart JH, McCormick WF. Anomalies of the human chest plate area: radiographic findings in a large autopsy population. Am J Forensic Med Pathol. 1988;9:348-54.

6. Ogden JA, Conlogue GJ, Bronson ML, Jensen PS. Radiology of postnatal skeletal development. Skeletal Radiol. 1979;4:18995. 